\title{
Cryolithionite as a novel pseudocapacitive electrode material for lithium-ion capacitors
}

Lukas Ladenstein $^{[\mathrm{a}] \#}$, Xuexue $\operatorname{Pan}^{[\mathrm{b}]}$ \# , Daniel Knez ${ }^{[\mathrm{c}]}$, Martin Philipp ${ }^{[\mathrm{a}]}$, Gerald Kothleitner $^{[\mathrm{c}]}$, Günther J. Redhammer ${ }^{[\mathrm{d}]}$, Qamar Abbas ${ }^{[\mathrm{a}, \mathrm{e}]^{*}}$, Daniel Rettenwander ${ }^{[\mathrm{a}, \mathrm{f}]^{*}}$

[a] L. Ladenstein, Dr. M. Philipp, Dr. Q. Abbas, Prof. Dr. Daniel Rettenwander, Institute of Chemistry and Technology of Materials, Graz University of Technology Graz, Austria

E-mail: qamar.abbas@tugraz.at; daniel.rettenwander@ntnu.at

${ }^{[b]}$ Dr. X. Pan, Guangdong Engineering Technology Research Center of Low Carbon and Advanced Energy Materials, Institute of Semiconductors, South China Normal University, Guangzhou 510631, China

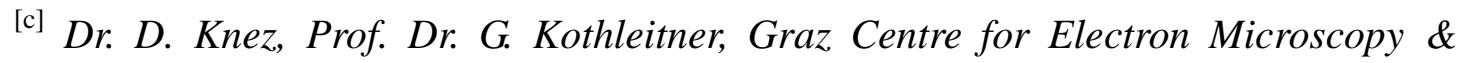
Institute of Electron Microscopy and Nanoanalysis, Graz University of Technology, Graz, Austria

[d] Prof. Dr. G. J. Redhammer, Department of Chemistry \& Physics of Materials, University of Salzburg, Salzburg, Austria

${ }^{[\mathrm{e}]}$ Dr. Q. Abbas, Institute of Chemistry and Technical Electrochemistry, Faculty of Chemical Technology, Poznan University of Technology, Poznan, Poland

${ }^{[\mathrm{f}]}$ Prof. Dr. Daniel Rettenwander, Department of Material Science and Engineering \& International Christian Doppler Laboratory for Solid State Batteriesg, NTNU Norwegian University of Science and Technology, Trondheim, Norway, Trondheim, Norway

${ }^{\#}$ Authors, L. Ladenstein and X. Pan, equally contributed to this work. 


\begin{abstract}
Lithium-ion insertion/deinsertion in anode at slow rates limits the power performance of energy storage devices. Here, a new pseudocapacitive electrode with high reversible capacity during cycling has been proposed for a lithium-ion capacitor. The lithium-fluoride garnet, namely $\mathrm{Na}_{3} \mathrm{Fe}_{2} \mathrm{Li}_{3} \mathrm{~F}_{12}$, is obtained via precipitation from an aqueous solution at room temperature using abundant materials and exhibits a high discharge capacity of $746 \mathrm{mAh} / \mathrm{g}$. After the first charging cycle, energy is stored via fast pseudocapacitive faradaic reactions which are facilitated by the nanocrystalline transport pathways with no structural modification to the electrode. The high stability window of F-garnet allows extracting cell voltages of $2.2-3.2 \mathrm{~V}$ in a lithium-ion capacitor where it is coupled with a porous carbon-based positive electrode, with a high energy efficiency of $93 \%$ maintained for 10000 charge/discharge cycles. This study opens new research direction concerning pseudocapacitive anode materials for the enhanced power performance and even replacing the traditional battery-like anode materials.
\end{abstract}

Keywords: F-garnet $\bullet$ pseudocapacitance $\bullet$ anode material $\bullet$ high power $\bullet$ lithium-ion capacitor 


\section{Introduction}

Metal-ion capacitors (MICs) are suitable for applications where high energy density along with high power is needed, e.g., regenerative braking, stop/start systems, or peak-power shaving ${ }^{[1-4]}$. In such applications, a high-power performance is desirable to relieve the coupled battery system from stress during peak power demand and enhance its operational life ${ }^{[5,6]}$. Therefore, new materials with fast charge/discharge characteristics are needed to improve the rates at which energy is stored and delivered. There is a growing need in the energy storage market to develop devices with high power and improved cycle life in order to lower the cost per Wh as well as the overall cost per cycle ${ }^{[7,8]}$. A prime example of MICs is the lithium-ion capacitor (LIC) that fills the energy gap between lithium-ion batteries (LIBs) and traditional electric double-layer capacitors (EDLCs). In contrast to $150-200 \mathrm{Wh} / \mathrm{kg}$ for LIBs, and 3-7 $\mathrm{Wh} / \mathrm{kg}$ for EDLCs, the LICs display 50-60 Wh/kg at high C-rates and cycle-life up to 0.5 million cycles ${ }^{[9-13]}$. Nevertheless, their power density is much lower than the EDLCs and the main bottleneck is the low efficiency of battery-like electrodes or anodes. Since the second electrode in these devices is made from high surface area carbon, the rate of charge storage at this electrode is high due to the physical charging of electric double-layer (EDL).

Currently, the generally accepted structure of LICs is a battery-type anode with a constant narrow potential range and a capacitor-type positive electrode with a broad linear potential range ${ }^{[14-17]}$. Devices with this structure have clear constraints in the 
charging and discharging process. The lowest potential of the positive electrode potential should be greater than $2.2 \mathrm{~V}$ vs. $\mathrm{Li} / \mathrm{Li}^{+}$to avoid the formation of solid electrolyte interface (SEI) film on the surface of the positive electrode active materials (e.g., activated carbon) ${ }^{[18-20]}$. Moreover, the highest potential of the cathode material should be lower than the oxidation potential of the electrolyte (e.g., $4.3 \mathrm{~V}$ vs. $\mathrm{Li} / \mathrm{Li}^{+}$) [21]. In terms of the negative electrode, its main problem is that the lithium ions are consumed to form the SEI film and the $\mathrm{Li}^{+}$inserted into the structure of the anodic host during the $1^{\text {st }}$ discharge ${ }^{[22,23]}$. Until now, the two most popular approaches utilize additional metal lithium electrodes and sacrificial materials (also called lithium-containing additives) mixed with activated carbon in the positive electrode ${ }^{[24-26]}$. When the irreversible capacity of the negative electrode material is large or the coulombic efficiency is low, the prelithiation process is satisfied because the metal lithium electrode can provide a large number of lithium ions. However, this process requires the two-step assembly of LICs, which increases the expenditure and reduces the possibility to use this strategy in a commercial way. On the contrary, sacrificial materials are suitable for anode materials with small irreversible capacity or high coulombic efficiency ${ }^{[24,27]}$. The advantage of using sacrificial materials is that the device only needs to be assembled once, reducing the cost of additional steps. However, because the mass of the sacrificial material is calculated based on the mass and the first discharge capacity of the anode material, and the practical capacity of the sacrificial material to remove lithium ions, the added sacrificial material in the positive electrode will significantly increase the mass of the positive electrode, 
thereby raising the thickness of the positive electrode to enhance the internal resistance of the positive electrode. In addition, after prelithiation, the oxidation products of the sacrificial material can stay inside the device and may negatively affect the performance of the device ${ }^{[28]}$. A second very important issue for battery-type anodes is the narrow potential range in which the charge-discharge curve of the anode material should be stable even at high current densities. Therefore, the voltage range of the device can be determined based on the above requirements. The last significant issue is that in the study of LICs, it is very important to balance the mass of the positive electrode due to the different kinetic processes of the positive and negative electrodes ${ }^{[21,29,30]}$. It can affect the cycle life and energy density of the device. For junior researchers to study LICs, it is recommended to use positive and negative electrode active materials with a mass ratio of $1: 1^{[31-33]}$.

Recently, Glushenkov et al. ${ }^{[16]}$ proposed a new and interesting structure of LICs (upside-down cells), which consists of a battery-type cathode with a constant narrow potential range and a capacitive negative electrode with a broad linear potential range. This device structure may eliminate prelithiation techniques because the cathode is a lithium-containing battery-type material. Indeed, we can assume that during the cycling of LICs, the huge available area of the activated carbon below $1.6 \mathrm{~V}$ vs. $\mathrm{Li} / \mathrm{Li}^{+}$ accelerates the decomposition of the electrolyte, thereby forming a SEI film on the surface of the active material, plugging the micropores, increasing the resistance and allowing the generation of gases, with severe consequences on the degradation of the 
electrode and the entire cell ${ }^{[34]}$. However, either classical or upside-down structure of LICs uses battery-type materials, which often experience volume expansion during cycling, resulting in poor cycle life of devices. Pseudocapacitive materials react with lithium ions and exhibit redox reactions into the near-surface (e.g., $\mathrm{RuO}_{2}, \mathrm{MnO}_{2}$ ) or their interlayer spacing (e.g., $\mathrm{MoS}_{2}, \mathrm{WS}_{2}, \mathrm{Ti}_{3} \mathrm{C}_{2}$ ), which can maintain an intact structure after long cycles ${ }^{[9,35]}$. Based on the two constructions of existing LICs and the properties of pseudocapacitive materials, we propose an additional concept of LICs. In this device, there is a pseudocapacitive material negative electrode with a broad linear potential range and a capacitive material positive electrode with a constant narrow potential range.

Cryolithionite, with the formula $\mathrm{Na}_{3} \mathrm{Al}_{2} \mathrm{Li}_{3} \mathrm{~F}_{12}$, is a unique natural mineral of the fluoride garnet group that occurs in hydrothermal deposits associated with minerals of other alumino-fluorides (e.g., Ivigtut, Greenland) ${ }^{[36,37]}$. In the last several decades, some mineralogical and crystallographic efforts were undertaken to substitute $\mathrm{Al}$ in $\mathrm{Na}_{3} \mathrm{Al}_{2} \mathrm{Li}_{3} \mathrm{~F}_{12}$ by third-row transition metals, such as $\mathrm{Fe}, \mathrm{Co}, \mathrm{Ni}, \mathrm{Ti}, \mathrm{V}, \mathrm{Cr}$, as well as other elements, such as Sc, Ga, In, and $\mathrm{Rh}^{[38-41]}$. Surprisingly, Cryolithionite has not received any attention for energy storage applications despite belonging to the garnet group, which is known to be one of the most promising groups of materials for solid electrolytes, e.g., $\mathrm{La}_{3} \mathrm{Zr}_{2} \mathrm{Li}_{7} \mathrm{O}_{12}$, used in Li-ion batteries today (see Fig. 1a) ${ }^{[42,43]}$. Although Li-oxide garnets are well known as solid electrolytes, they can also be used as electrode material if a redox active center is present as Goodenough and coworkers 
demonstrated ${ }^{[44]}$. They were able to reversibly insert $4 \mathrm{Li}^{+}$per formula unit $\left(\mathrm{Li}_{3} \mathrm{Nd}_{3} \mathrm{~W}^{6+}{ }_{2} \mathrm{O}_{12}+4 \mathrm{Li}^{+}+2 \mathrm{e}^{-} \leftrightarrow \mathrm{Li}_{7} \mathrm{Nd}_{3} \mathrm{~W}^{4+}{ }_{2} \mathrm{O}_{12}\right)$ into the oxide-garnet lattice with an initial capacity of $105 \mathrm{mAh} / \mathrm{g}$. In the case for $\mathrm{Li}$-fluoride garnets $\left(\mathrm{Na}_{3} \mathrm{M}_{2} \mathrm{Li}_{3} \mathrm{~F}_{12}\right.$, with $\mathrm{M}=\mathrm{Ti}, \mathrm{V}, \mathrm{Cr}, \mathrm{Mn}, \mathrm{Fe}, \mathrm{Co}, \mathrm{Ni}$, and $\mathrm{Cu}$ ) theoretical gravimetric and volumetric capacities of up to $260 \mathrm{mAh} / \mathrm{g}$ and $745 \mathrm{mAh} / \mathrm{cm}^{3}$ could be potentially achieved, respectively. A further advantage of cryolithionites is the possibility to synthesize the material at room temperature ${ }^{[45]}$ - this makes its preparation low cost, which is particularly important to drop the price per $\mathrm{kWh}$. Cryolithionite is a fluoride that tends to form strong Li-F bonds, which is a disadvantage in terms of Li mobility, hence, Li insertion. However, this could become an attractive material for energy storage by inducing pseudocapacitive characteristics due to the $\mathrm{Fe}^{2+} / \mathrm{Fe}^{3+}$ redox activity present in the crystal lattice.

Therefore, we synthesized phase pure nano-crystalline $\mathrm{Na}_{3} \mathrm{Fe}_{2} \mathrm{Li}_{3} \mathrm{~F}_{12}$ (NFLF) powder at room temperature by precipitation from an aqueous solution and thoroughly characterized it by using a wide spectrum of characterization techniques. Indeed, we found that NFLF displays pseudocapacitive properties after first lithium insertion, which fits well to the fast EDL charging of high surface area nanoporous carbon electrodes. Thus, the designed LIC displays high cycle life and rate performance that makes it adaptable for a range of applications to quickly harvest and deliver energy. Moreover, the LIC device assembled with NFLF and activated carbon operates between $2.2-3.2 \mathrm{~V}$, displays a constant capacitance of ca. $26 \mathrm{~F} / \mathrm{g}$ and high energy 
efficiency during 10000 galvanostatic charge/discharge cycles.

\section{Experimental Section}

\subsection{Synthesis.}

$\mathrm{Na}_{3} \mathrm{Fe}_{2} \mathrm{Li}_{3} \mathrm{~F}_{12}$ was synthesized using $10 \mathrm{~mL}$ of $\mathrm{NaOH}$, and stoichiometric amounts of $\mathrm{LiOH}$ and $\mathrm{NaFeO}_{2}$. During stirring a precipitation was formed, which was then dissolved by adding $\mathrm{HCl}$ until a $\mathrm{pH}$ value of 2 was achieved. The solution $10 \mathrm{~mL}$ of $5 \%$ HF (1:10 in methanol) was added. The fluoride garnet then precipitated overnight and was purified by washing with methanol 3 times.

\subsection{X-ray diffraction.}

To check if the synthesis was successful X-ray powder diffraction measurements were carried out using a Bruker D8 Advance diffractometer operating with $\mathrm{CuK} \alpha$ radiation. Data were collected at angles $2 \theta$ ranging from $10^{\circ}$ to $100^{\circ}$. X-ray powder diffraction data were refined using the Fullprof-suite of programs

\subsection{Mössbauer spectroscopy.}

The Fe oxidation states and possible cationic distributions were determined by ${ }^{57} \mathrm{Fe}$ Mössbauer spectroscopy using an apparatus (Halder Electronics, Germany) in horizontal arrangement $\left({ }^{57} \mathrm{Fe} \mathrm{Co} / \mathrm{Rh}\right.$ single-line thin source, constant acceleration model with symmetric triangular velocity shape, a multi-channel analyzer with 1024 channels, regular velocity calibration against metallic $\mathrm{Fe}$ ). Data evaluation was performed using the program Recoil allowing the use of a full static hyperfine 
interaction Hamiltonian analysis with Lorentzian-shaped doublets, but also a Voigt-based hyperfine parameter distribution analysis.

\subsection{Electrochemical analysis.}

To investigate the ion conduction of $\mathrm{Na}_{3} \mathrm{Fe}_{2} \mathrm{Li}_{3} \mathrm{~F}_{12}$ (NFLF), Electrochemical Impedance Spectroscopy (EIS) and polarization experiments were conducted. Therefore, dried NFLF powder was uniaxially pressed into pellets (diameter $d=5$ $\mathrm{mm}$, thickness $h \sim 1 \mathrm{~mm}$ ) under a force of $0.5 \mathrm{kN}$. Au blocking electrodes with a thickness of $50 \mathrm{~nm}$ were applied on both sides of the pellet with a Leica EM SCD 050 sputter device. EIS was recorded between $-60{ }^{\circ} \mathrm{C}$ to $240{ }^{\circ} \mathrm{C}$ in $10{ }^{\circ} \mathrm{C}$ steps using a Novocontrol Concept 80 broadband dielectric spectrometer, covering a frequency range from $10 \mathrm{mHz}$ to $10 \mathrm{MHz}$. To avoid any influence of oxygen or water, the measurements in the sample cell (BDS 1200, Novocontrol) were controlled by a QUATRO cryosystem (Novocontrol) with a stream of freshly evaporated $\mathrm{N}_{2}$ gas. Polarization measurements were conducted at $20{ }^{\circ} \mathrm{C}$ in a climate chamber at a potential of $100 \mathrm{mV}$. To avoid any influence of moisture during the measurement, the pellets were assembled in Swagelok-cells under Ar atmosphere in the glove box (MBraun labmaster pro sp, <0.1ppm $\mathrm{O}_{2},<0.1 \mathrm{ppm} \mathrm{H}_{2} \mathrm{O}$ ).

\subsection{Cell assembling and electrochemical testing.}

The electrode was prepared by $140 \mathrm{mg} \mathrm{Na} \mathrm{Fe}_{2} \mathrm{Li}_{3} \mathrm{~F}_{12}$ mixed with $50 \mathrm{mg}$ Super C65, $10 \mathrm{mg}$ Knyar 761 (PVDF) and $0.95 \mathrm{ml} \mathrm{N}-$ Methyl-2-pyrrolidon. The obtained slurry was cast on a Cu-foil with a thickness of $100 \mu \mathrm{m}$ and dried at $60^{\circ} \mathrm{C}$ for $12 \mathrm{~h}$ in a 
climate chamber. $10 \mathrm{~mm}$ diameter electrodes were stamped out of the copper foil and were dried again under reduced pressure of $\left(10^{-4} \mathrm{mbar}\right)$ for $12 \mathrm{~h}$. Free-standing carbon electrodes were prepared by mixing $90 \mathrm{wt} \%$ of the microporous YP80F carbon (from Kuraray) with $5 \mathrm{wt} \%$ carbon black (C65 from Imerys), and $5 \mathrm{wt} \%$ of polytetrafluoroethylene ( $60 \%$ dispersion in water from $3 \mathrm{M}$ Chemicals) in isopropanol. The mixture was stirred at $78^{\circ} \mathrm{C}$, and a dough was obtained, pressed and rolled on a glass plate into a thin sheet. The electrode sheet was dried at $120^{\circ} \mathrm{C}$ and calendared to achieve a final thickness of about $150 \mu \mathrm{m}$, from which the disc electrodes were punched out. The electrolyte was $1 \mathrm{~mol} / \mathrm{L} \mathrm{LiPF}_{6}$ (origin, grade) in EC:DMC solvent (origin, grade) soaked in a GF/A glassy fiber that acts as a separator. The pre-lithiation of F-garnet was performed in a separate cell versus metallic lithium as counter and reference electrodes. For three-electrode cell measurements and prelithiation of NFLF electrode, Swagelok-type cells with a $\mathrm{Li} / \mathrm{Li}^{+}$reference electrode were assembled and lithium intercalation was carried out at a slow scan rate of $0.05 \mathrm{mV} / \mathrm{s}$. Cyclic voltammetry at a scan rate from $0.05 \mathrm{mV} / \mathrm{s}$ up to $50 \mathrm{mV} / \mathrm{s}$ and galvanostatic charge/discharge measurements were carried out up to $100 \mathrm{~mA} / \mathrm{g}$. The prelithiated F-garnet (negative electrode) and activated carbon (positive electrode) were coupled in a separate Swagelok-type cell where electrodes were pasted onto the stainless steel cylinders acting as current collectors. The hybrid LICs were assembled by using about $150 \mu \mathrm{L}$ electrolyte and the working to counter electrode mass ratio of 1:1 was used. The specific current and capacitance values are expressed per total mass of electrodes including the binder and conductivity enhancer. The resulting rate capability, cycle 
life and the self-discharge measurements were carried out at maximum reachable voltage. The LIC cell was charged at the maximum voltage of $3.2 \mathrm{~V}$ for 4 hours before the open circuit during self-discharge measurements. Electrochemical measurements on supercapacitor cells were performed with a VMP3 multichannel potentiostat/galvanostat (Bio-Logic Instruments).

\subsection{TEM.}

TEM sample preparation was performed via focused ion beam (FIB) milling with Ga ions using a FIB/SEM Dual Beam Microscope FEI NOVA 200. The lift out and initial milling step was performed with $30 \mathrm{kV}$ ions and the final milling step was done at 5 $\mathrm{kV}$. The resulting lamellae were mounted onto an Omniprobe copper-based lift-out grid and directly transferred to the microscope. STEM observations were carried out by a probe corrected FEI TITAN ${ }^{3} \mathrm{G} 2$ microscope operated at $300 \mathrm{kV}$ in scanning mode. The microscope is equipped with a SuperX four-quadrant EDX detector. Selected area electron diffraction (SAED) experiments were performed using a FEI Tecnai F20 microscope, operated at $200 \mathrm{kV}$.

\section{Results and discussion}

\subsection{The crystal chemistry.}

NFLF was prepared via precipitation from an aqueous solution (see Supplementary Fig. 1 and experimental details). A fine brownish powder was obtained. The corresponding X-ray diffraction pattern of NFLF is shown in Fig. $1 b$. 
The data can be indexed on basis of the standard garnet structure in the space group $I a \overline{3} d$ in close relation to the structure of cryolithionite $\mathrm{Na}_{3} \mathrm{Al}_{2} \mathrm{Li}_{3} \mathrm{~F}_{12}{ }^{[37]}$ and synthetic $\mathrm{Na}_{3} \mathrm{Fe}_{2} \mathrm{Li}_{3} \mathrm{~F}_{12}{ }^{[46]}$, no indications were found for a symmetry reduction caused by $\mathrm{H}-\mathrm{Li}$ exchange as a result from the synthesis in an aqueous solution as known for, e.g., Li-oxide garnets ${ }^{[47]}$. Observed lattice parameters are $a=12.4118(2) \AA$ and are of similar size to those of the material obtained by Takeda, et al. ${ }^{[45]}$, also by precipitation from an aqueous solution with $a=12.407(2) \AA$. In the structure of $\mathrm{Na}_{3} \mathrm{Fe}_{2} \mathrm{Li}_{3} \mathrm{~F}_{12}$, sodium occupies the $24 c$ site with an eightfold fluor atom coordination, the octahedrally coordinated $16 a$ site hosts iron, while Li resides on the $24 d$ position and is in tetrahedral coordination. Based on the Rietveld refinements (Fig. 1b) on the powder diffraction data, the $24 c$ and the $16 a$ site appear to be fully occupied, however, a slight Li deficit might be present at the $24 d$ site, due to the low scattering contrast of $\mathrm{Li}$, but this cannot be fully validated (see SI for more details). ${ }^{57} \mathrm{Fe}$ Mössbauer spectroscopy in Fig. 1c proved the presence of solely ferric iron in octahedral coordination, no $\mathrm{Fe}^{2+}$ is present, nor is there any hint for $\mathrm{Fe}^{3+}$ on other sites. Rather broad lines and slightly asymmetric shape indicate some distributions of local distortion environments around the iron atoms maybe related to nano-scale nature of the particles ( $40 \mathrm{~nm}$; see Fig. 1d showing NFLF particles embedded in the composite electrode), hence surface terminated Fe contributions will get significant (see SI for more details). Such structural merit may facilitate the lithium insertion/deinsertion that fundamentally contributes to pseudocapacitive energy storage of the anode. Except for the Fe element, other elements such as $\mathrm{Na}, \mathrm{O}, \mathrm{F}$ and $\mathrm{C}$ are uniformly 
distributed in the electrode.

\subsection{The electrochemical performance.}

The cyclic voltammogram of the NFLF electrode recorded at a scan rate of $0.05 \mathrm{mV} / \mathrm{s}$ down to a vertex potential of $0.1 \mathrm{~V}$ vs. $\mathrm{Li} / \mathrm{Li}^{+}$(obtained with a three-electrode setup) is shown in Fig. 2a. Three reduction peaks can be observed, whereby the first peak at $0.98 \mathrm{~V}$ vs. $\mathrm{Li} / \mathrm{Li}^{+}$can be assigned to the SEI formation, the second and third prominent peaks at $0.8 \mathrm{~V}$ and $0.39 \mathrm{~V}$ vs. $\mathrm{Li} / \mathrm{Li}^{+}$are associated with lithium insertion of NFLF structure. However, these reactions may partially change the morphology (i.e., amorphization) of NFLF. The overlap of the 2nd and 3rd cycles reveals the good reversibility of Li storage after the 1st cycle, suggesting that a stable SEI film is formed during the initial cycle. In Fig. 2b, even at high scan rates, the peaks related to lithium insertion/deinsertion maintain their original shape and become broader compared to peaks at low scan rates. The cathodic peaks become steeper due to diffusion-related polarization, and the anodic peaks shift to higher potentials with increasing scan rates. The storage mechanism of lithium for NFLF is firstly investigated by the Kinetic calculation. The CV data are collected at different scan rates (Fig. 2b), from which the ratio of the capacitive contribution could be obtained. Based on the equation of $i=a v^{b}$ between the current $(i)$ and scan rate $(v)$, the value of $b$ is determined by the slope of $\log (i)$ and $\log (v)$ curve, while the $b$-value close to 1.0 signifies that the electrochemical process is controlled by the capacitive response, whereas $b$-value close to 0.5 indicates the diffusion process is dominating. The 
$b$-value from the anodic or cathodic current at $0.8 \mathrm{~V}$ vs. $\mathrm{Li}^{\prime} / \mathrm{Li}^{+}$is calculated to be 0.942 or 0.916 (Fig. 2c), respectively. Interestingly, the $b$ value is between 0.5 and 1 , much close to 1 , indicating that the capacitive effect may occupy the main parts of the charge storage behavior. In general, the capacitance process includes adsorption capacitance and pseudocapacitance ${ }^{[35]}$. Actually, materials with pseudocapacitive properties also participate in the diffusion process ${ }^{[35]}$. Thus, the detailed quantification of capacitive contribution is measured according to the Dunn's method ${ }^{[48]}$ to acquire the actual ratio and the following equation $i=k_{1} v+k_{2} v^{1 / 2}$, where $i$ represents the current value, $k_{1}$ and $k_{2}$ are the constant, $v$ is the scan rate, $k_{1} v$ and $k_{2} v^{1 / 2}$ are the adsorption contribution and pseudocapacitive contribution, respectively. The total specific capacitance at a fixed ratio of total capacitance shows an adsorption/pseudocapacitive process (red/black part) of $53.5 \% / 46.5 \%$ at $0.2 \mathrm{mV} \mathrm{s}^{-1}$ in Fig. 2d. Furthermore, the adsorption contribution in Fig. 2e is $64.5 \%, 72.0 \%, 78.4 \%$, $85.2 \%, 88.2 \%, 92.0 \%$ or $94.8 \%$ with the raising of scan rate $(0.5,1,2,5,10,20,50$ $\mathrm{mV} \mathrm{s}^{-1}$ ), while the pseudocapacitive contribution is $35.5 \%, 28.0 \%, 21.6 \%, 14.8 \%$, $11.8 \%, 8.0 \%$ or $5.2 \%$. The ratio of capacitive contribution is quite limited by the adsorption process, indicating that the pseudocapacitive process plays a small part in the charge storage behaviors. The first galvanostatic charge-discharge curve in Fig. $2 \mathrm{f}$ shows three plateaus at $1.1 \mathrm{~V}, 0.8 \mathrm{~V}$ and $0.2 \mathrm{~V}$ vs. $\mathrm{Li} / \mathrm{Li}^{+}$corresponding to the first $\mathrm{CV}$ cathodic process. The first discharge or charge capacity is $746 \mathrm{mAh} / \mathrm{g}$ or $529 \mathrm{mAh} / \mathrm{g}$, respectively, which would result in an initial coulombic efficiency of $70.9 \%$. A similar behavior has been reported for Fe-based anodes during lithium insertion ${ }^{[49,50]}$. The 
coulomb efficiency of 25 cycles is in the range of $82 \%$, which can be seen from Supplementary Fig. 2. Specifically, after 1st cycle of SEI film formation, only the discharge time or discharge capacity from the 2 nd cycle to the 4 th cycle decreases slightly, while the discharge time or discharge capacity from the 5th cycle to the 25 th cycle is almost unchanged. This clearly shows that no side reaction or irreversible faradaic deposition occurs after the successful formation of the SEI film.

\subsection{The electrochemical evaluation in a lithium-ion hybrid capacitor.}

Since the low initial coulombic efficiency could consume a large number of lithium ions in LICs without prelithiation to form the SEI film and insertion material structure, we first used the metal lithium electrode as the counter electrode to prelithiate the NFLF working electrode, and then the prelithiated NFLF electrode was removed from the pristine device and used as the anode together with cathode in the new device to assemble a LIC. The charge/discharge curves of a LIC assembled in $1 \mathrm{~mol} / \mathrm{L} \mathrm{LiPF}_{6}$ in EC:DMC by coupling of lithium-inserted NFLF as anode and an activated porous carbon-based EDL electrode with the equal mass of NFLF and active carbon. The positive EDL electrode in Fig. 3a displays symmetric charge/discharge curves in a narrow potential window of $3.4-3.5 \mathrm{~V}$ vs $\mathrm{Li} / \mathrm{Li}^{+}$. Additionally, the minimum potential of the positive electrode is $2.2 \mathrm{~V}$ vs. $\mathrm{Li} / \mathrm{Li}^{+}$, preventing any possible SEI formation on the AC surface ${ }^{[18-20]}$, while the maximum potential of the latter electrode is below the electrolyte oxidation limit of $4.3 \mathrm{~V}$ vs. $\mathrm{Li} / \mathrm{Li}^{+}{ }^{[21]}$. The narrow potential window of the EDL electrode compared to the pseudocapacitive electrode 
(enlarged potential window of 0.1 to $1.0 \mathrm{~V}$ vs. $\mathrm{Li} / \mathrm{Li}^{+}$) indicates the high capacity and charge storage capability. Moreover, the minimum potential of the negative electrode is higher than $0 \mathrm{~V}$ vs. $\mathrm{Li} / \mathrm{Li}^{+}$to avoid the lithium plating ${ }^{[51]}$. Nevertheless, a relatively larger potential window for the pseudocapacitive electrode indicates a lower capacity compared to the carbon electrode at $2.5 \mathrm{~mA} / \mathrm{g}$ (the specific current is based on the total mass of NFLF and carbon electrodes). The cell voltage shown in Fig. 3a indicates an overall symmetric charge/discharge behavior of the LIC confirming the contribution from both electrodes and verifying the pseudocapacitance and EDL capacitance for anode and cathode, respectively, which is the structure we proposed in the introduction. To demonstrate the advantages of our proposed LICs, a series of electrochemical properties will be tested and compared to the literature. An energy density of $41 \mathrm{Wh} / \mathrm{kg}$ and a power density of $0.61 \mathrm{~kW} / \mathrm{kg}$ has been estimated for the hybrid supercapacitor. Despite the gravimetric capacitance and energy values calculated per total mass of electrodes including the binder and conductivity additive, they are still comparable to the traditional Li-ion cells using a battery-like negative electrode $^{[52]}$. The LIC was cycled between $3.2-2.2 \mathrm{~V}$ at a high specific current of 50 mA/g for 10000 galvanostatic charge/discharge cycles. During the cycling period, galvanostatic charge-discharge curves were collected after every 1000 cycles in Fig. $3 \mathrm{~b}$ and charge-discharge time decreases slightly during cycling, where a small yet gradual decrease of capacitance can be seen and the energy efficiency remains at the level of $91 \%$ (Fig. 3c). This decrease could be due to the interactions on the electrode surface where faradaic reactions occur, and these reversible reactions might be 
affected by electrolyte depletion or structural changes in the electrode over longer cycling periods (see below). Nevertheless, the symmetric charge/discharge curve after 10000 cycles and nearly constant capacitance of $26 \mathrm{~F} / \mathrm{g}$ (per total mass of electrodes) during the cycling period indicates the stability, efficiency, and reversibility of faradaic processes. Another indication of LIC stable performance is shown by the self-discharge behavior in Fig. 3d, where the overall cell voltage decreases by only $\Delta U=0.16 \mathrm{~V}$ after an open circuit at $3.2 \mathrm{~V}$ for $24 \mathrm{~h}$. A negligible voltage loss at high voltage is also confirmed by the individual electrode potential profiles, where the positive carbon electrode displays a nearly constant evolution of potential. The overall LIC self-discharge is mainly sourced from the NFLF pseudocapacitive electrode. Since the pseudocapacitive faradaic processes are dependent on the short pathways for the Li-ion movement, any contaminant in the electrode acting as a parasitic reaction site could drive minor potential and capacity loss ${ }^{[53]}$. On the other hand, the activated carbon electrode, which is a highly porous electrode, stores charges physically at the EDL, and a constant potential during the open circuit indicates nearly no involvement of parasitic reactions. Furthermore, the LIC was tested via galvanostatic charge/discharge at high current from $2.5 \mathrm{~mA} / \mathrm{g}$ up to $100 \mathrm{~mA} / \mathrm{g}$ by the gradual increase of specific current while keeping the cell voltage from $2.2-3.2 \mathrm{~V}$. The GCD curves in Supplementary Fig. 3 further confirm the well-matched mass on both electrodes as the isosceles triangle-shaped profiles are maintained even with an 80-fold increase of the current density. Then, the rate performance is calculated based on these curves where $33.7 \%$ of the capacitance is maintained with a larger increase 
of the current density. Supplementary Fig. 3 and Supplementary Fig. 4a, 4b show that the symmetry of galvanostatic charge/discharge is maintained throughout the high current applications with very small ohmic loss indicated by the profile of NFLF negative electrode at fully charge state. Importantly, the two-electrode current-voltage curve in Supplementary Fig. 4c has a square-shape, which indicates the charge storage like a capacitor, which is a cumulative effect of both the capacitive carbon and the pseudocapacitive garnet electrodes. In addition, the presence of a narrow potential window for the positive carbon electrode and an enlarged potential window of the pseudocapacitive negative electrode shows a capacitance disparity between the two electrodes. However, the square-shaped voltage-current curve is evident of the fast charge/discharge of supercapacitor device. Cell voltage vs. log $t$ curve in Supplementary Fig. 4d shows the capacitive discharge mechanism which is related to the faradaic processes of the negative pseudocapacitive electrode and adsorption behavior of activated carbon positive. This behavior is in line with the nearly constant potential window of the positive carbon electrode which does not decay over an open circuit.

The structural alteration of NFLF as observed during electrochemical testing might be related to the insertion of Li-ions into the particle, which causes a volume mismatch between the new phase near the surface and the existing phase in the interior of the particle. The volume mismatch and the associated accumulated stress occurs if the relaxation kinetics is slower (i.e., NFLF has a conductivity of $\sim 10^{-14} \mathrm{~S} \mathrm{~cm}^{-1}$, see 
Supplementary Fig. 5 than the transfer rate, which induces high chemo-mechanical strain potentially causing plastic deformation, mechanical fracturing and even amorphization, as similarly observed for, e.g., $\mathrm{LiCO}_{2}{ }^{[54]}$ and $\mathrm{Si}{ }^{[55]}$. The gradual decrease in particle size resulting in an amorphization of the electrode material is evident from the ex-situ XRD diffraction pattern of the electrode shown in Fig. 4a. After cycling only minor indications of crystalline NFLF can be observed as indicated by the decreased intensity of the characteristic reflexes in the XRD pattern of NFLF. Further evidence is given by the TEM micrographs shown in Fig. 4b indicating a significant amorphization of the NFLF, while a granular morphology is still visible. Selected area electron diffraction (SAED) data shown in Fig. 4c also exhibits a high degree of amorphization and only faint signs of crystallinity can be discerned in some regions. The observed diffractions spots can be assigned to the (116) planes of NFLF with a lattice spacing of 2.01 A. EDS mapping shown in Fig. 4d furthermore reveals an almost homogenous distribution of all constituents ( $\mathrm{Na}, \mathrm{Fe}$, and $\mathrm{F}$ ) within the sample. Although there are some indications of NFLF amorphization that mainly occurs during prelithiation step, its impact on the overall hybrid supercapacitor is expected to be negligible and is the focus of further studies.

\section{Conclusion}

Herein, we present a novel anode material with pseudocapacitive properties and no capacity loss during cycling for the LIC. The nano-scale iron-derivate of cryolithionite, $\mathrm{Na}_{3} \mathrm{Fe}_{2} \mathrm{Li}_{3} \mathrm{~F}_{12}$, has been synthesized phase pure from abundantly 
available precursors by precipitation from an aqueous solution without any heat treatment. The electrochemical evaluation indicates that $\mathrm{Na}_{3} \mathrm{Fe}_{2} \mathrm{Li}_{3} \mathrm{~F}_{12}$ exhibits a high discharge capacity of $746 \mathrm{mAh} / \mathrm{g}$. After the first charging cycle, energy is stored via fast pseudocapacitive faradaic reactions which are facilitated by the nanocrystalline transport pathways to the electrode. This material displays a high electrochemical stability window that allows extracting a large cell voltage range from $2.2 \mathrm{~V}$ to $3.2 \mathrm{~V}$ in a LIC where it is coupled with a positive electrode made from porous carbon for electric double-layer charge storage. The fast charging/discharging of the garnet-based electrode via pseudocapacitive and adsorption storage mechanisms fits well with the fast EDL charging/discharging of nanoporous carbon electrodes. The most important aspect is the high energy efficiency of $93 \%$ maintained for 10000 galvanostatic charge/discharge cycles which is superior to the state-of-the-art LICs. This study opens a new direction of research concerning pseudocapacitive anode materials for enhancing the power performance and even replacing the traditional battery-like insertion anode materials.

\section{Acknowledgement}

D. R. acknowledges financial support by Austrian Federal Ministry for Digital and Economic Affairs, the National Foundation for Research, Technology and Development and the Christian Doppler Research Association (Christian Doppler Laboratory for Solid-State Batteries). Q. A. acknowledges the funding from the Austrian Science Fund (FWF) under the Lise Meitner project M 2576-N37. Q. A. and 
D. R. thanks Bernhard Gollas for his support as well as the ICTM to host the research performed within this study.

\section{Declaration of Competing Interest}

The authors declare that they have no known competing financial interests or personal relationships that could have appeared to influence the work reported in this paper.

\section{CRediT authorship contribution statement}

Lukas Ladenstein: Investigation, Methodology, Formal analysis, Writing - original draft. Xuexue Pan: Investigation, Formal analysis, Software, Visualization, Writing review \& editing. Daniel Knez: Data curation, Formal analysis, Methodology. Martin Philipp: Visualization, Investigation, Methodology. Gerald Kothleitner: Validation, Methodology. Günther J. Redhammer: Formal analysis, Validation. Qamar Abbas: Conceptualization, Formal analysis, Validation, Methodology, Supervision, Writing review \& editing. Daniel Rettenwander: Conceptualization, Methodology, Formal analysis, Validation, Supervision, Funding acquisition, Writing - review \& editing, Project administration. 


\section{References}

[1] G. G. Amatucci, F. Badway, A. D. Pasquier, T. Zheng, An Asymmetric Hybrid Nonaqueous Energy Storage Cell, J. Electrochem. Soc. 148 (2001) A930-A939. https://doi.org/10.1149/1.1383553

[2] M.-S. Park, Y.-G. Lim, S. M. Hwang, J. H. Kim, J.-S. Kim, S. X. Dou, J. Cho, Y.-J. Kim, Scalable Integration of $\mathrm{Li}_{5} \mathrm{FeO}_{4}$ towards Robust, High-Performance Lithium-Ion Hybrid Capacitors, ChemSusChem 7 (2014) 3138-3144. https://doi.org/10.1002/cssc.201402397

[3] L. Cheng, X.-L. Li, H.-J. Liu, H.-M. Xiong, P.-W. Zhang, Y.-Y. Xia, Carbon-coated $\mathrm{Li}_{4} \mathrm{Ti}_{5} \mathrm{O}_{12}$ as a high rate electrode material for $\mathrm{Li}$-ion intercalation, J. Electrochem. Soc. 154 (2007) A692-A697. https://doi.org/10.1149/1.2736644

[4] T. Aida, K. Yamada, M. Morita, An advanced hybrid electrochemical capacitor that uses a wide potential range at the positive electrode, Electrochem. Solid-State Lett. 9 (2006) A534-A536. https://doi.org/10.1149/1.2349495

[5] K. Naoi, S. Ishimoto, J. Miyamoto, W. Naoi, Second generation 'nanohybrid supercapacitor': evolution of capacitive energy storage devices, Energy Environ. Sci. 5 (2012) 9363-9373. https://doi.org/10.1039/c2ee21675b

[6] J. Ajuria, E. Redondo, M. Arnaiz, R. Mysyk, T. Rojo, E. Goikolea, Lithium and sodium ion capacitors with high energy and power densities based on carbons from recycled olive pits, J. Power Sources 359 (2017) 17-26. 
https://doi.org/10.1016/j.jpowsour.2017.04.107

[7] B. Anothumakkool, S. Wiemers- Meyer, D. Guyomard, M. Winter, T. Brousse, J. Gaubicher, Cascade- Type Prelithiation Approach for Li- Ion Capacitors, Adv. Energy Mater. 9 (2019) 1900078. https://doi.org/10.1002/aenm.201900078

[8] https://www.jsrmicro.be/emerging-technologies/lithium-ion-capacitor/products/ulti mo-lithium-ion-capacitor-laminate-cell, accessed on 8 May 2021.

[9] T. S. Mathis, N. Kurra, X. Wang, D. Pinto, P. Simon, Y. Gogotsi, Energy storage data reporting in perspective-guidelines for interpreting the performance of electrochemical energy storage systems, Adv. Energy Mater. 9 (2019) 1902007. https://doi.org/10.1002/aenm.201902007

[10] G. E. Blomgren, The development and future of lithium ion batteries, J. $\begin{array}{lllll}\text { Electrochem. } & \text { Soc. } & 164 \quad \text { (2017) }\end{array}$ https://doi.org/10.1149/2.0251701jes

[11] J. Janek, W. G. Zeier, A solid future for battery development, Nat. Energy 1 (2016) 16141. https://doi.org/10.1038/nenergy.2016.141

[12] P. G. Bruce, S. A. Freunberger, L. J. Hardwick, J.-M. Tarascon, Li-O ${ }_{2}$ and Li-S batteries with high energy storage, Nat. Mater. 11 (2012) 19-29. https://doi.org/10.1038/NMAT3191

[13] M. Arnaiz, D. Shanmukaraj, D. Carriazo, D. Bhattacharjya, A. Villaverde, M. Armand, J. Ajuria, A transversal low-cost pre-metallation strategy enabling $23 \mid \mathrm{P}$ a g e 
ultrafast and stable metal ion capacitor technologies, Energy Environ. Sci. 13 (2020) 2441-2449. https://doi.org/10.1039/D0EE00351D

[14] J. Ding, W. Hu, E. Paek, D. Mitlin, Review of Hybrid Ion Capacitors: From Aqueous to Lithium to Sodium, Chem. Rev. 118 (2018) 6457-6498. https://doi.org/10.1021/acs.chemrev.8b00116

[15] H. Wang, C. Zhu, D. Chao, Q. Yan, H. J. Fan, Nonaqueous Hybrid Lithium-Ion and Sodium-Ion Capacitors, Adv. Mater. $29 \quad$ (2017) 1702093. https://doi.org/10.1002/adma.201702093

[16] A. M. Glushenkov, A. V. Ellis, Cell Configurations and Electrode Materials for Nonaqueous Sodium-Ion Capacitors: The Current State of the Field, Adv. Sustain. Syst. 2 (2018) 1800006. https://doi.org/10.1002/adsu.201800006

[17] D. Cericola, R. Kötz, Hybridization of rechargeable batteries and electrochemical capacitors: Principles and limits, Electrochim. Acta 72 (2012) 1-17. http://dx.doi.org/10.1016/j.electacta.2012.03.151

[18] J. P. Zheng, Energy Density Theory of Lithium-Ion Capacitors, J. Electrochem. Soc. 168 (2021) 080503. https://doi.org/10.1149/1945-7111/ac180f

[19] S. Dsoke, Expanding the Cathodic Potential Window of Activated Carbon Electrodes in a Lithium-Salt Containing Electrolyte, Batteries\& Supercaps 215 (2018) 1. https://doi.org/10.1002/batt.201800084

[20] W. J. Cao, J. P. Zheng, The Effect of Cathode and Anode Potentials on the 
Cycling Performance of Li-Ion Capacitors, J. Electrochem. Soc. 160 (2013) A1572-A1576. https://doi.org/10.1149/2.114309jes

[21] S. Dsoke, B. Fuchs, E. Gucciardi, M. Wohlfahrt-Mehrens, The importance of the electrode mass ratio in a Li-ion capacitor based on activated carbon and $\mathrm{Li}_{4} \mathrm{Ti}_{5} \mathrm{O}_{12}$, J. Power $\quad$ Sources $282 \quad$ (2015) 385-393. https://doi.org/10.1016/j.jpowsour.2015.02.079

[22] F. Holtstiege, A. Wilken, M. Winter, T. Placke, Running out of lithium? A route to differentiate between capacity losses and active lithium losses in lithium-ion batteries, Phys. Chem. Chem. Phys. 19 (2017) 25905-25918. https://doi.org/10.1039/C7CP05405J

[23] S. Jurng, Z. L. Brown, J. Kim, B. L. Lucht, Effect of electrolyte on the nanostructure of the solid electrolyte interphase (SEI) and performance of lithium metal anodes, Energy Environ. Sci. 11 (2018) 2600-2608. https://doi.org/10.1039/C8EE00364E

[24] K. Zou, W. Deng, P. Cai, X. Deng, B. Wang, C. Liu, J. Li, H. Hou, G. Zou, X. Ji, Prelithiation/Presodiation Techniques for Advanced Electrochemical Energy Storage Systems: Concepts, Applications, and Perspectives, Adv. Funct. Mater. 31 (2021) 2005581. https://doi.org/10.1002/adfm.202005581

[25] F. Holtstiege, P. Bärmann, R. Nölle, M. Winter, T. Placke, Pre-Lithiation Strategies for Rechargeable Energy Storage Technologies: Concepts, Promises 
and Challenges, Batteries 4 (2018) 4. https://doi.org/10.3390/batteries4010004

[26] L. Jin, C. Shen, A. Shellikeri, Q. Wu, J. Zheng, P. Andrei, J.-G. Zhang, J. P. Zheng, Progress and perspectives on pre-lithiation technologies for lithium ion capacitors, Energy Environ. Sci. $13 \quad$ (2020) 2341-2362. https://doi.org/10.1039/D0EE00807A

[27] D. Dewar, A. M. Glushenkov, Optimisation of sodium-based energy storage cells using pre-sodiation: a perspective on the emerging field, Energy. Environ. Sci. 14 (2021)1380-1401. https://doi.org/10.1039/D0EE02782K

[28] T, Zhang, R, Wang, B, He, J, Jin, Y, Gong, H. Wang, Recent advances on pre-sodiation in sodium-ion capacitors: A mini review, Electrochem. Commun. 129 (2021) 107090. https://doi.org/10.1016/j.elecom.2021.107090

[29] J.-J. Yang, C.-H. Choi, H.-B. Seo, H.-J. Kim, S.-G. Park, Voltage characteristics and capacitance balancing for $\mathrm{Li}_{4} \mathrm{Ti}_{5} \mathrm{O}_{12}$ /activated carbon hybrid capacitors, $\begin{array}{lllll}\text { Electrochim. } & \text { Acta } & 86 & \text { 277-281. }\end{array}$ https://doi.org/10.1016/j.electacta.2012.02.060

[30] X. Sun, X. Zhang, H. Zhang, N. Xu, K. Wang, Y. Ma, High performance lithium-ion hybrid capacitors with pre-lithiated hard carbon anodes and bifunctional cathode electrodes, J. Power Sources 270 (2014) 318-325. https://doi.org/10.1016/j.jpowsour.2014.07.146

[31] J. P. Zheng, The Limitations of Energy Density of Battery/Double-Layer 
Capacitor Asymmetric Cells, J. Electrochem. Soc. 4 (2003) A484-A492. https://doi.org/10.1149/1.1559067

[32] P. Jeżowski, O. Crosnier, E. Deunf, P. Poizot, F. Béguin, T. Brousse, Safe and recyclable lithium-ion capacitors using sacrificial organic lithium salt, Nat. Mater. 17 (2018) 167-173. https://doi.org/10.1038/nmat5029

[33] K. Wasiński, P. Półrolniczak, M. Walkowiak, Proof-of-concept study of a new type sodium-ion hybrid electrochemical capacitor with organic electrolyte, $\begin{array}{lllll}\text { Electrochim. } & \text { Acta } & 259 & \text { 850-854. }\end{array}$ https://doi.org/10.1016/j.electacta.2017.11.036

[34] T. Zhang, B. Fuchs, M. Secchiaroli, M. Wohlfahrt-Mehrens, S. Dsoke, Electrochemical behavior and stability of a commercial activated carbon in various organic electrolyte combinations containing Li-salts, Electrochim. Acta 218 (2016) 163-173. https://doi.org/10.1016/j.electacta.2016.09.126

[35] Y. Wang, Y. Song, Y. Xia, Electrochemical capacitors: mechanism, materials, systems, characterization and applications, Chem. Soc. Rev. 45 (2016) 5925-5950. https://doi.org/10.1039/C5CS00580A

[36] G. Menzer, Die Kristallstrnktur von Kryolithionit, Zeitschrift für Krist. - Cryst. Mater. 75 (1930) 265-287. https://doi.org/10.1515/zkri-1930-0118

[37] S. Geller, Refinement of the crystal structure of cryolithionite, $\left\{\mathrm{Na}_{3}\right\}\left[\mathrm{Al}_{2}\right]\left(\mathrm{Li}_{3}\right) \mathrm{F}_{12}$, The American Mineralogist, 56 (1971) 18-23. 
[38] R. H. Langley, G. D. Sturgeon, Lattice parameters and ionic radii of the oxide and $\begin{array}{lllllll}\text { fluoride garnets, J. } & \text { Solid } & \text { State } & \text { Chem. } 30 & \text { (1979) } & \text { 79-82. }\end{array}$ https://doi.org/10.1016/0022-4596(79)90132-4

[39] P. H. R. dePape, J. Portier, G. Gauther, C. R.. Acad. SC. Paris 1967, 265, $1244-1246$.

[40] P. H. R. dePape, J. Portier, J. Grannec, G. Gauther, C. R. Acad. SC. Paris 1967, $269,1120-1121$.

[41] S. CHAMBERLAIN, L. R. CORRUCCINI, Magnetic properties of Ti, $\mathrm{Cr}$ and $\mathrm{Fe}$ fluoride garnets, J. Phys. Chem. Solids 58 (1997) 899-901. https://doi.org/10.1016/S0022-3697(96)00223-5

[42] R. Murugan, V. Thangadurai, W. Weppner, Fast Lithium Ion Conduction in Garnet-Type $\mathrm{Li}_{7} \mathrm{La}_{3} \mathrm{Zr}_{2} \mathrm{O}_{12}$, Angew. Chemie Int. Ed. 46 (2007) 7778-7781. https://doi.org/10.1002/anie.200701144

[43] V. Thangadurai, S. Narayanan, D. Pinzaru, Garnet-type solid-state fast Li ion conductors for Li batteries: critical review, Chem. Soc. Rev. 43 (2014) 4714-4727. https://doi.org/10.1039/C4CS00020J

[44] H. Xie, K.-S. Park, J. Song, J. B. Goodenough, Reversible lithium insertion in the garnet framework of $\mathrm{Li}_{3} \mathrm{Nd}_{3} \mathrm{~W}_{2} \mathrm{O}_{12}$, Electrochem. Commun. 19 (2012) 135-137. https://doi.org/10.1016/j.elecom.2012.03.014

[45] Y. Takeda, M. Sone, Y. Suwa, M. Inagaki, S. Naka, Synthesis of fluoride garnets $28 \mid \mathrm{P}$ a g e 
$\left\{\mathrm{Na}_{3}\right\}\left[\mathrm{M}^{3+}{ }_{2}\right]\left(\mathrm{Li}_{3}\right) \mathrm{F}_{12}(\mathrm{M}=\mathrm{Al}, \mathrm{Cr}$, and $\mathrm{Fe})$ from aqueous solution and their properties, J. Solid State Chem. $20 \quad$ (1977) 261-265. https://doi.org/10.1016/0022-4596(77)90162-1

[46] W. Massa, B. Post, D. Babel, Verfeinerung der Granatstruktur des Natrium-Lithium-Eisen (III) fluorids $\mathrm{Na}_{3} \mathrm{Li}_{3} \mathrm{Fe}_{2} \mathrm{~F}_{12}$, ZEITSCHRIFT FUR Krist. 158 (1982) 299-306. https://doi.org/10.1524/zkri.1982.158.12.299

[47] C. Hiebl, D. Young, R. Wagner, H. M. R. Wilkening, G. Redhammer, D. Rettenwander, Proton Bulk Diffusion in Cubic $\mathrm{Li}_{7} \mathrm{La}_{3} \mathrm{Zr}_{2} \mathrm{O}_{12}$ Garnets as Probed by Single X-ray Diffraction, J. Phys. Chem. C 123 (2019) 1094-1098. https://doi.org/10.1021/acs.jpcc.8b10694

[48] V. Augustyn, J. Come, M. A. Lowe, J. W. Kim, P. L. Taberna, S. H. Tolbert, H. D. Abruña, P. Simon, B. Dunn, High-rate electrochemical energy storage through $\mathrm{Li}^{+}$intercalation pseudocapacitance, Nat. Mater. 12 (2013) 518-522. https://doi.org/10.1038/nmat3601

[49] Y. Xiang, Z. Yang, S. Wang, M. S. A. Hossan, J. Zu, N. A. Kumar, Y. Yamauchi, Pseudocapacitive behavior of the $\mathrm{Fe}_{2} \mathrm{O}_{3}$ anode and its contribution to high reversible capacity in lithium ion batteries, Nanoscale 10 (2018) 18010-18018. https://doi.org/10.1039/C8NR04871A

[50] E. Kendrick, A. Swiatek, J. Barker, Synthesis and characterisation of iron tungstate anode materials, J. Power Sources 189 (2009) 611-615. 
https://doi.org/10.1016/j.jpowsour.2008.09.103

[51] Q. Liu, C. Du, B. Shen, P. Zuo, X. Cheng, Y. Ma, G. Yin, Y. Gao, Understanding undesirable anode lithium plating issues in lithium-ion batteries, RSC Adv. 6 (2016) 88683-88700. https://doi.org/10.1039/c6ra19482f

[52] H. Kim, M.-H. Cho, M.-H. Kim, K.-Y. Park, H. Gwon, H. Lee, K. C. Roh, K. Kang, A Novel High-Energy Hybrid Supercapacitor with an Anatase $\mathrm{TiO}_{2}-$ Reduced Graphene Oxide Anode and an Activated Carbon Cathode, Adv. Energy Mater. 3 (2013) 1500-1506. https://doi.org/10.1002/aenm.201300467

[53] H. A. Andreas, Self-Discharge in Electrochemical Capacitors: A Perspective Article, J. Electrochem. Soc. $162 \quad$ (2015) A5047-A5053. https://doi.org/10.1149/2.0081505jes

[54] H. Wang, Y.-I. Jang, B. Huang, D. R. Sadoway, Y.-M. Chiang, TEM study of electrochemical cycling- induced damage and disorder in $\mathrm{LiCoO}_{2}$ cathodes for rechargeable lithium batteries, J. Electrochem. Soc. 146 (1999) 473-480. https://doi.org/10.1149/1.1391631

[55] P. Limthongkul, Y.-I. Jang, N. J. Dudney, Y.-M. Chiang, Electrochemically-driven solid-state amorphization in lithium-metal anodes, J. $\begin{array}{lllll}\text { Power } & \text { Sources } & 119 & \text { 604-609. }\end{array}$ https://doi.org/10.1016/S0378-7753(03)00303-3 


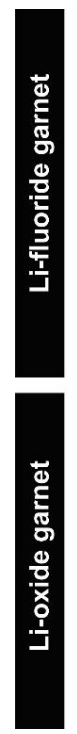

a

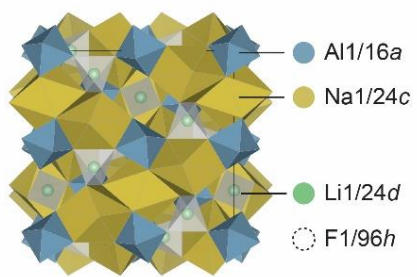


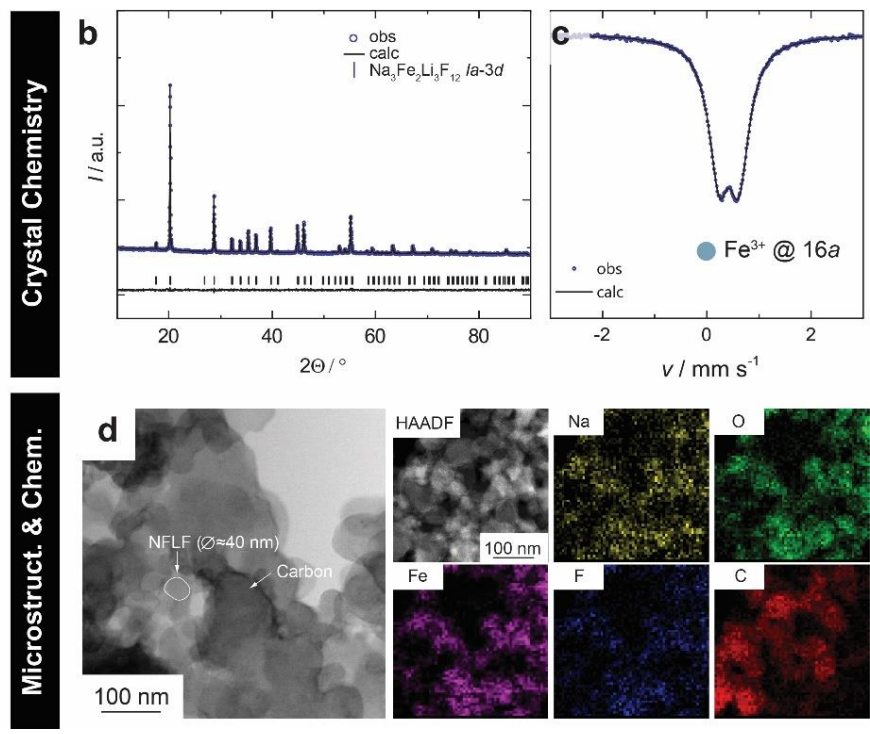

Fig. 1. Crystal chemistry and Morphology. a $\mathrm{Na}_{3} \mathrm{Al}_{2} \mathrm{Li}_{3} \mathrm{~F}_{12}$ and $\mathrm{La}_{3} \mathrm{Zr}_{2} \mathrm{Li}_{7} \mathrm{O}_{12}$ garnets (Space group: $I a-3 d$ ). ${ }^{5,6} \mathrm{In}$ Li-fluoride garnet structure the $\mathrm{F}^{-}$are located at the general crystallographic position $96 h$ (not shown), which forms a $\mathrm{F}^{-}$framework with interstices occupied by $\mathrm{Na}^{+}$at the eight-fold coordinated position $24 c$ (A-site), by $\mathrm{Al}^{3+}$ (or $\mathrm{Fe}^{3+}$ in case of $\mathrm{Na}_{3} \mathrm{Fe}_{2} \mathrm{Li}_{3} \mathrm{~F}_{12}$ ) at the six-fold coordinated position $16 a$ (B-site), and by $\mathrm{Li}^{+}$at the four-fold coordinated $24 d$ position (C-site). The high Li-ion conductivity of Li-oxide garnets is caused by the occupation of interstices within the oxide framework (six-fold coordinated $48 g$ and $96 h$ position) with extra $\mathrm{Li}^{+}$forming a 3-D pathway providing high Li-ion diffusivity. b The observed (obs), calculated (calc), and difference patterns (obs-calc) for the Rietveld refinement from powder X-ray diffraction of $\mathrm{Na}_{3} \mathrm{Fe}_{2} \mathrm{Li}_{3} \mathrm{~F}_{12}$. The short vertical lines below the profiles mark the reflection positions of all possible Bragg reflections of this phase. c Mössbauer spectrum of $\mathrm{Na}_{3} \mathrm{Fe}_{2} \mathrm{Li}_{3} \mathrm{~F}_{12}$ shows doublet, which could be assigned to $\mathrm{Fe}^{3+}$ at the $16 a$ site. d STEM annular bright-field (ABF) image of a composite electrode containing $\mathrm{Na}_{3} \mathrm{Fe}_{2} \mathrm{Li}_{3} \mathrm{~F}_{12}$ particles. The image series depicts a STEM HAADF image of a representative area of the electrode and corresponding EDS elemental maps. 

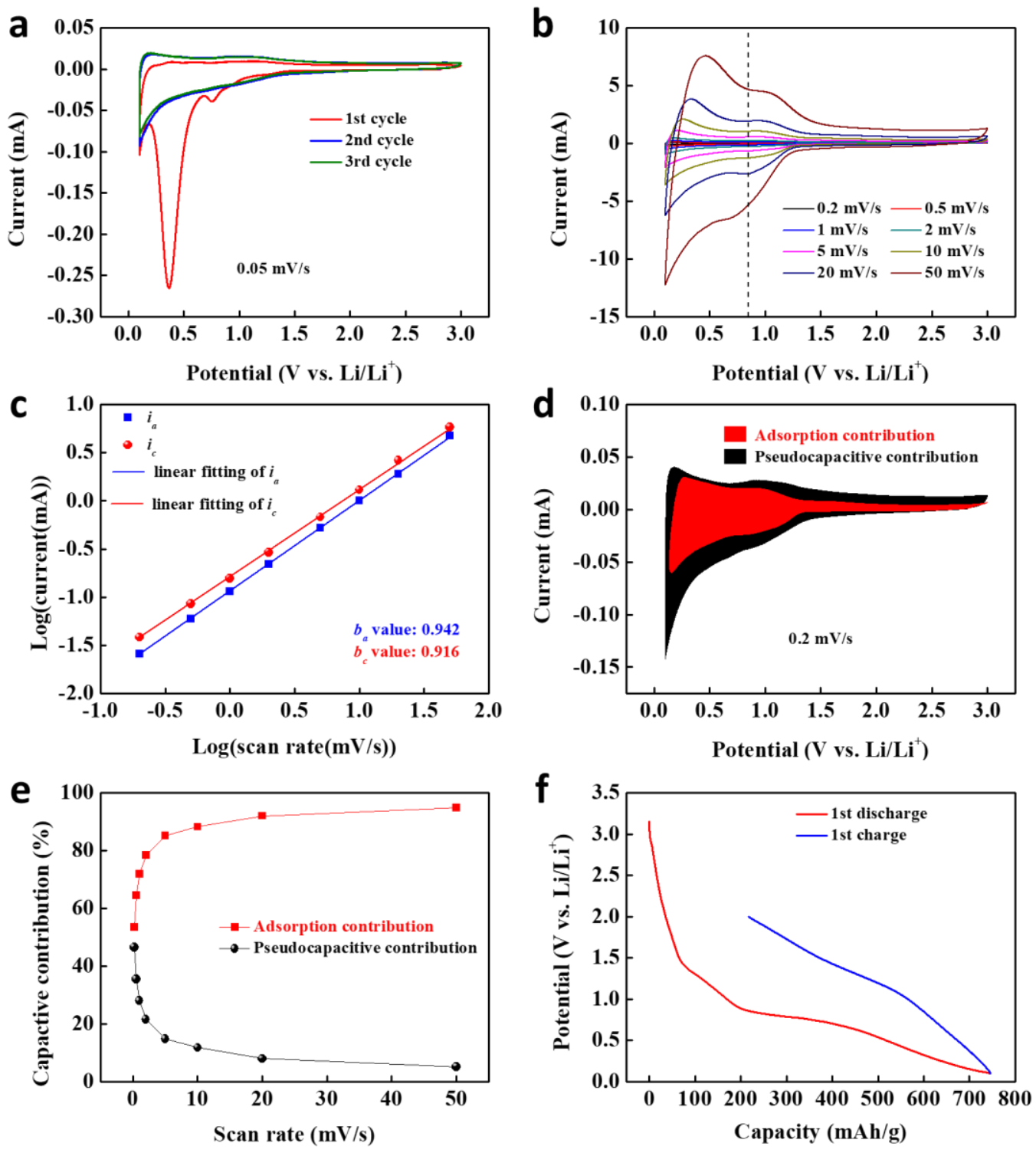

Fig. 2. Electrochemical performance of $\mathbf{N a}_{3} \mathbf{F e}_{2} \mathbf{L i}_{3} \mathbf{F}_{12}$. a Initial cyclic voltammograms (scan rate $=0.05 \mathrm{mV} / \mathrm{s}$ ) during the first lithium insertion in $\mathrm{Na}_{3} \mathrm{Fe}_{2} \mathrm{Li}_{3} \mathrm{~F}_{12}$ which was repeated for $3 \mathrm{CVs}$ down to a vertex potential of $0.1 \mathrm{~V}$ vs. $\mathrm{Li} / \mathrm{Li}^{+}$. b CV curves of $\mathrm{Na}_{3} \mathrm{Fe}_{2} \mathrm{Li}_{3} \mathrm{~F}_{12}$ at different scan rates from $0.2 \mathrm{mV} / \mathrm{s}$ to $50 \mathrm{mV} / \mathrm{s}$. c determination of the $b$ value using the relationship between anodic or cathodic currents and scan rates at the potential of $0.8 \mathrm{~V}$ vs. $\mathrm{Li} / \mathrm{Li}^{+}$. d separation of the adsorption contribution and pseudocapacitive contribution at $0.2 \mathrm{mV} / \mathrm{s}$. e contribution ratio of the adsorption contribution and pseudocapacitive contribution vs. scan rate. $\mathbf{f}$ the first galvanostatic discharge-charge of $\mathrm{Na}_{3} \mathrm{Fe}_{2} \mathrm{Li}_{3} \mathrm{~F}_{12}$ at $25 \mathrm{~mA} / \mathrm{g}$. 

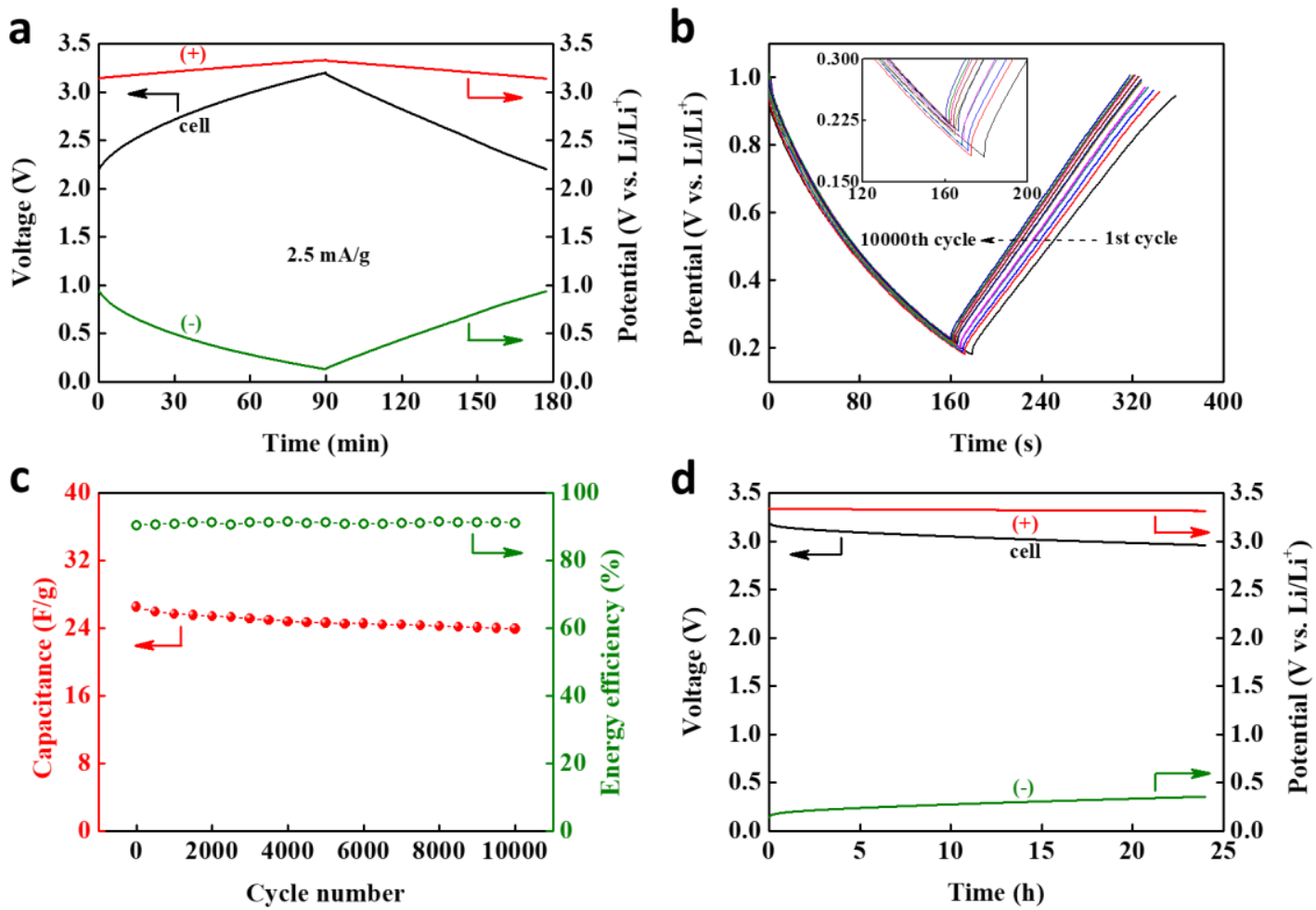

Fig. 3. Electrochemical performance of lithium-ion capacitors. a galvanostatic charge/discharge curve of a hybrid supercapacitor between $2.2-3.2 \mathrm{~V}$ with carbon/ $\mathrm{Na}_{3} \mathrm{Fe}_{2} \mathrm{Li}_{3} \mathrm{~F}_{12}$ setup, where $\mathrm{LiPF}_{6}$ (in EC:DMC) served as the electrolyte, and lithium was used as the reference electrode. The current density is expressed per total mass of electrodes. $\mathbf{b}$ the electrochemical behavior of negative $\mathrm{Na}_{3} \mathrm{Fe}_{2} \mathrm{Li}_{3} \mathrm{~F}_{12}$ electrode during 10000 galvanostatic charge/discharge cycles. c capacitance and energy efficiency of $\mathrm{Na}_{3} \mathrm{Fe}_{2} \mathrm{Li}_{3} \mathrm{~F}_{12} /$ carbon hybrid supercapacitor during galvanostatic charge/discharge cycling at $50 \mathrm{~mA} / \mathrm{g}$ (collected after every 500 cycles). Capacitance is expressed per total mass of NFLF and carbon electrodes including the binder and conductivity enhancer. d self-discharge behavior of hybrid cell and electrodes during an open circuit period after charging up to $3.2 \mathrm{~V}$. 

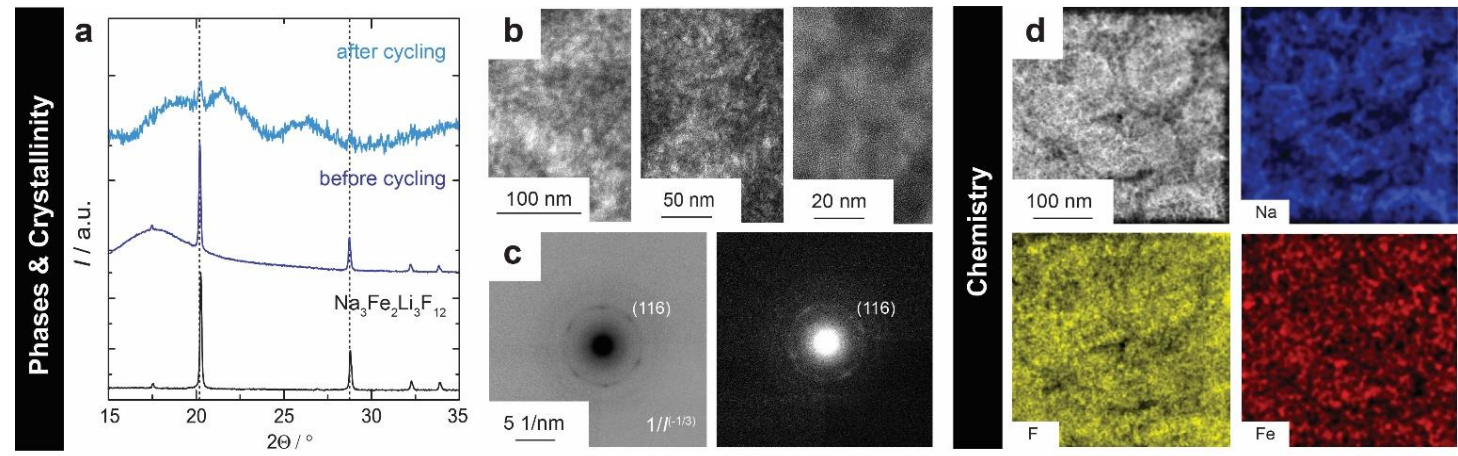

Fig. 4. Post-mortem analysis of lithium-ion hybrid capacitor. a X-ray diffraction pattern of $\mathrm{Na}_{3} \mathrm{Fe}_{2} \mathrm{Li}_{3} \mathrm{~F}_{12}$ powder as prepared (reference), and in a composite electrode before and after cycling. A significant amorphization of the particles is evident. Just small indications of the main reflexes of $\mathrm{Na}_{3} \mathrm{Fe}_{2} \mathrm{Li}_{3} \mathrm{~F}_{12}$ can be detected after cycling. $\mathbf{b}$ TEM bright field images at different magnifications, showing the granular morphology. c Selected area electron diffraction (SAED) giving an only minor indication of crystalline $\mathrm{Na}_{3} \mathrm{Fe}_{2} \mathrm{Li}_{3} \mathrm{~F}_{12}$; SAED intensity values are transformed by $\mathrm{I}^{(-1 / 3)}$ for better visibility of the weak reflections. d STEM EDS elemental maps show the spatial distribution of all constituents $(\mathrm{Na}, \mathrm{Fe}$ and $\mathrm{F})$ of cryolithionite. 